\title{
Analisis Perilaku Mean Dataset Perubahan Garis Pantai pada Hasil Spasialtemporal Metode Empirical Orthogonal Function (EOF)
}

\author{
IAPF. Imawati ${ }^{1}$, M. Sudarma ${ }^{2}$, INS. Kumara ${ }^{3}$
}

\begin{abstract}
The purpose of this study is to apply EOF method on shoreline change resulting spatialtemporal analysis mode 1 and also to to prove the mean behavior on the spatial or temporal of its EOF outcomes. The data used was obtained from shoreline coordinates of shp file of the Bali island map and the result of breaking waves study, by using a one-dimensional modeling yielded dataset or prediction shoreline changes during 91 months. Calculation EOF 1, the input matrix or dataset was initially not reduced by the mean but EOF 2 vice versa. Each matrix receive the same treatment were calculated covariance, eigen value, eigen vector and principal component. EOF calculations obtained the last five eigen value, the last five eigen vector, trace, principal component and variant data. Based on the results obtained were compared parameters of two matrices mentioned before.
\end{abstract}

Spatially results both of EOF 1 and EOF 2 shows the same eigen vector represented by the first mode of eigen vector. Similarly, the eigen value, trace and variance of data, produce the same information. Significant difference occurs in the principal component (temporal). EOF 1 shows that the value of the first month produces a positive value, second month until month 91th output are minus. EOF 2 shows the value of the principal component the first month until the 37th month are in a positive position, then from month 38th to month 91th yielded negative results. Nevertheless EOF 1 and EOF 2 showed shoreline changes tend to be erosion.

Intisari - Tujuan dari penelitian ini adalah menerapkan metode EOF pada perubahan garis pantai sehingga menghasilkan analisis spasialtemporal mode ke-1 dan juga untuk membuktikan perilaku mean pada hasil spasial atau temporal hasil EOF tersebut. Data yang digunakan diperoleh dari koordinat garis pantai file shp dari peta pulau Bali dan hasil studi gelombang pecah, dengan menggunakan pemodelan satu dimensi menghasilkan dataset atau prediksi perubahan garis pantai selama 91 bulan. Perhitungan EOF 1, matriks input atau dataset awalnya tidak dikurangi dengan rata-rata tetapi EOF 2 sebaliknya. Setiap matriks menerima perlakuan yang sama dihitung covariance, eigen value, eigen vektor dan principal component. Dari perhitungan EOF diperoleh eigen value lima terakhir, eigen vcktor lima terakhir, trace, principal component dan variance data. Berdasarkan hasil yang diperoleh dibandingkan parameter dua matriks sebelumnya.

Secara spasial hasil EOF 1 ataupun EOF 2 menunjukkan nilai eigen vector yang sama yang diwakili oleh eigen vector mode pertama. Demikian pula pada eigen value, trace dan varian data, EOF 1 dan EOF 2 menghasilkan informasi yang sama. Perbedaan yang siginifikan terjadi pada principal component

\footnotetext{
${ }^{1}$ Mahasiswa, Program Pascasarjana Magister Teknik Elektro Universitas Udayana, Jalan P. B. Sudirman, Denpasar, Bali INDONESIA, e-mail: dayufebri@gmail.com)

2, 3 Dosen, Program Pascasarjana Magister Teknik Elektro Universitas Udayana, Jalan P. B. Sudirman, Denpasar, Bali INDONESIA, e-mail: sudarma@ee.unud..ac.id)
}

(temporal). Dari EOF 1 didapatkan bahwa nilai temporal bulan ke-1 menghasilkan nilai positif, bulan ke-2 hingga bulan ke-91 output bernilai minus. Pada EOF 2 nilai principal component ke1 hingga bulan ke-37 berada pada posisi positif, selanjutnya dari bulan ke-38 hingga bulan ke-91 menghasilkan nilai negatif. Meskipun demikian EOF 1 dan EOF 2 tetap menunjukkan garis pantai yang cenderung mengalami erosi.

Kata Kunci- Empirical Orthogonal Function, Principal Component Analysis, Perubahan garis pantai, Mean data spasialtemporal.

\section{Pendahuluan}

Perkembangan teknologi komputer sejalan dengan pertumbuhan kebutuhan manusia. Di segala bidang kehidupan, komputer, aplikasi, hingga metode pemecahan masalahnya (algoritma) akan membantu aktifitas yang dilakukan manusia. Mulai dari hal yang paling sederhana hingga hal yang kompleks. Misalnya saja peralatan rumah tangga yang digunakan sehari-hari hingga pengambilan keputusan suatu organisasi besar dapat didukung aplikasi komputer.

Karena manusia tidak dapat lepas dari lingkungan sekitar kehidupannya, dukungan komputer dan aplikasinya dapat berupa prediksi terhadap perubahan keadaan lingkungan sekitar sehingga tindakan pencegahan dapat dilakukan dan memungkinkan untuk mengurangi dampak yang ditimbulkan. Sebagai contoh untuk mengurangi pencemaran lingkungan dan dampak sampah bagi kesehatan manusia dibuatkan sebuah sistem pendukung keputusan pemilihan lokasi tempat pembuangan akhir sampah dengan menggunakan metode minmax inference fuzzy [1]. Dengan cuaca ekstrem seperti sekarang ini banjir bisa terjadi secara tidak terduga meskipun saat cuaca cerah. Untuk mengantisipasi bencana banjir tersebut dimulai dengan mengamati ketinggian air bendungan dengan aplikasi komputer, mikrokontroler ATMEGA-328PU, sensor HC-SR04 yang digabungkan dengan media sosial twitter, sehingga pantauan air dapat dilaporkan dan diketahui secara terkini oleh masyarakat [2]. Penerapan komputer yang lain di bidang lingkungan adalah pemetaan zona kedalaman air laut dengan memanfaatkan segmentasi citra satelit (penginderaan jauh) dengan clustering DBSCAN guna mendapatkan potret informasi bahari suatu daerah sebagai penunjang kebijakan bidang perikanan, perhubungan laut hingga pertambangan [3].

Dalam rangka monitoring, evaluasi serta pemutakhiran informasi erosi-abrasi garis pantai, komputer dan penerapannya digunakan untuk prediksi perubahan dan analisis perubahan garis pantai. Menurut Dabees pemodelan satu dimensi merupakan model berbasis proses yang sangat bagus pada sebagian besar aplikasi praktis karena mampu memprediksi perubahan dalam jangka panjang [4]. Model ini

1693 - 2951; e-ISSN: 2503-2372

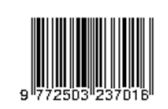


juga diterapkan pada penelitian prediksi perubahan garis Pantai Nusa Dua [5]. Sedangkan pada analisis perubahan lebih sering digunakan analisis perubahan dalam konteks ruang dan waktu. Salah satu metodenya adalah empirical orthogonal function (EOF). Berbeda dengan pemodelan satu dimensi yang berbasis proses, EOF berbasis pada data atau disebut data driven method. Keduanya dapat digunakan sehingga analisis yang dilakukan dapat saling melengkapi.

Metode EOF adalah teknik matematika yang dapat digunakan untuk menganalisis variasi temporal dan spasial dari set data. Alvarez dan Pan menyebutkan bahwa teknik EOF telah digunakan secara luas dalam berbagai disiplin ilmu sebagai contoh, metode EOF digunakan untuk prediksi atmosfer dan memprediksi suhu di permukaan laut [6]. Dengan EOF keterkaitan antara data temporal dan spasial dapat dipisahkan sehingga kombinasi fungsi linier yang sesuai dari ruang dan waktu pun dapat dihasilkan. EOF memungkinkan untuk mereproduksi perubahan garis pantai pada periode survey dengan menggunakan fungsi-fungsi orthogonal dengan jumlah yang lebih sedikit. Set fungsi yang disediakan diurutkan sehingga fungsi yang paling pertama baik komponen secara temporal dan spasial menjelaskan bagian paling banyak dari variabilitas data. Hal ini yang menyebabkan metode EOF sederhana dan objektif untuk menganalisis variasi garis pantai [6]. Analisis EOF juga digunakan oleh Kuriyama et al untuk melakukan penelitian di belakang sebuah submerged breakwater pantai Niigata dengan menggunakan sebuah model prediksi garis pantai [7]. Alvarez dan Pan mengusulkan model untuk prediksi morfologi jangka panjang komponen spasial dan temporal EOF pada sebuah model simulasi garis pantai [6]. Berbagai penelitian lain yang terkait penggunaan EOF untuk analisis perubahan garis pantai, antara lain: Arkwright dan Suntoyo melakukan analisis perubahan garis pantai di Bangkalan Madura [8], Luhwayudin et al menganalisis garis Pantai Kabupaten Tegal [9], Azhar et al menganalisis perubahan garis Pantai Tuban, Jawa Timur [10] dan Ivanoviq et al untuk analisis karakteristik perubahan garis Pantai Lebih di Gianyar [11].

Normalnya sebelum melakukan perhitungan EOF yang umumnya disebut sebagai principal component analysis (PCA) atau factor analysis, matriks inputan spasialtemporal harus dikurangi dengan mean data. Miranda et al menyebutkan bahwa pengurangan mean diperlukan pada PCA untuk memastikan bahwa principal component menggambarkan arah varians maksimum [12]. Jika pengurangan mean tidak dilakukan, principal component mode kesatu mungkin akan terkoresponden lebih atau kurang terhadap mean dari data. Mean nol dibutuhkan untuk menemukan sebuah basis yang akan meminimalkan mean square error dari perkiraan data.

Beberapa penelitian yaitu Arkwright dan Suntoyo, Azhar et al, Ivanoviq et al menyebutkan bahwa sebelum melakukan analisis EOF posisi garis pantai harus dikurangi dengan nilai posisi rata-rata [8],[10],[11] namun pada penelitian Alvarez dan Pan disebutkan bahwa dalam menggunakan teknik EOF, untuk sistem yang dekat dengan keadaan setimbang, nilai mean dari parameter dapat dikurangi sebelum menerapkan EOF [6],[13]. Jika nilai mean tidak dihapus dalam analisis
EOF, komponen EOF pertama akan menunjukkan perilaku mean dan komponen kedua, ketiga dan komponen berikutnya akan mengikuti. Penelitian ini menyebutkan, karena selama studi diasumsikan kedalaman laut berevolusi dari keadaan inisial ke keadaan setimbang karena itu dipertimbangkan untuk tidak menghilangkan nilai mean untuk analisis EOF.

Penelitian ini dilakukan untuk mengetahui bagaimana pengaruh pengurangan mean ini terhadap dataset awal terhadap hasil spasial maupun temporal dari EOF. Pada penelitian ini akan dilakukan analisis terhadap data garis pantai dengan EOF. Dataset awal yang sama akan diberikan perlakuan berbeda sebelum menerapkan EOF. EOF 1 dataset awal tanpa dikurangi mean atau pantai diasumsikan pantai tetap berevolusi selama penelitian berlangsung. EOF 2 dataset awal dikurangi mean atau pantai diasumsikan dalam keadaan sekitar setimbang, kemudian dibandingkan parameter hasil EOF 1 dan EOF 2 untuk mendapatkan kesimpulan. Algoritma EOF yang diimplementasikan adalah hasil modifikasi kode Matlab dari Shi et al [14].

\section{RUANG LINGKUP}

Miranda et al juga menyebutkan bahwa pengurangan mean terhadap data inputan awal selain bermaksud sebagai inisialisasi awal juga untuk mengoptimalkan solusi atau mendekatkan hasil dengan nilai aproksimasi [12]. Root mean square error (RMSE) pada penelitian ini tidak dapat dihitung karena data awal (data time series) sebagai acuan atau referensi tidak ada. Hal ini berarti bahwa hasil penelitian ini hanya akan mampu memperlihatkan atau membandingkan hasil ketika data inputan awal dikurangi mean data dengan data inputan awal tidak dikurangi mean data. Hasil penelitian ini akan dapat membuktikan adanya perilaku mean di hasil EOF namun belum mampu memberikan keputusan apakah hasil EOF yang matriks inputannya tidak dikurangi dengan mean data ataukah hasil EOF yang matriks inputannya yang dikurangi mean data akan menjadi hasil EOF yang terbaik (RMSE minimum). Selain itu dari 5 mode yang dihasilkan pada penelitian ini juga hanya akan membahas mode pertama karena mode pertama ini sudah dapat mewakili informasi mayoritas data asli.

\section{EMPIRICAL ORTHOGONAL FUNCTION (EOF)}

Metode EOF mengkalkulasi sebuah set fungsi orthogonal atau komponen spasial dan temporal, yang dapat digunakan untuk merekonstruksi data set original pada semua point selama periode penelitian. Hal ini memiliki kesamaan proses dengan dekomposisi Fourier tanpa harus memaksakan solusi berupa sinus dan kosinus [6].

Oleh karena itu dengan menggunakan metode EOF memungkinkan untuk mereproduksi perubahan garis pantai pada periode survey dengan menggunakan fungsi-fungsi orthogonal dengan jumlah yang lebih sedikit. Set fungsi yang disediakan diurutkan sehingga fungsi yang paling pertama baik komponen secara temporal dan spasial menjelaskan bagian paling banyak dari variabilitas data. Hal ini yang menyebabkan metode EOF sederhana dan objektif untuk menganalisis variasi garis pantai. Asumsikan F (n, m) adalah 
matriks yang berisi data ' $n$ ' poin dari variabel ruang selama ' $m$ ' survei waktu. Metode EOF menyediakan fungsi X (m) dan T (n) yang dibuat:

$$
d(x=n, t=m)=\sum_{j} X(n, i) T(m, i) a(i)
$$

$\mathrm{d}(\mathrm{x}=\mathrm{n}, \mathrm{t}=\mathrm{m})$ adalah variabel yang direkonstruksi, (i) adalah sebuah faktor skala dan i mewakili jumlah. Untuk mendapatkan X (m) dan $\mathrm{T}(\mathrm{n})$, nilai eigen dan vektor harus diselesaikan dengan menggunakan:

$$
\begin{aligned}
& {[A-\lambda I] X=0 \text { dengan: } A=F \times F^{T}} \\
& {[B-\lambda I] X=0 \text { dengan: } B=F^{T} \times F}
\end{aligned}
$$

Ukuran matriks $A=[\mathrm{n} \times \mathrm{n}]$ dan $\mathrm{B}=[\mathrm{m} \times \mathrm{m}] . \lambda$ adalah matriks eigen value, yang menyediakan informasi tentang bobot masing-masing eigen vector pada total varians dari data. Oleh karena itu memungkinkan untuk menentukan berapa banyak komponen atau mode yang akan digunakan dalam merekonstruksi ke tingkat akurasi tertentu. Sebagai metode, EOF mampu memisahkan variasi spasial dari variasi temporal sehingga memungkinkan untuk menentukan secara jelas titik dimana erosi yang lebih besar akan terjadi dan juga bisa menjelaskan kapan perubahan besar yang terjadi [6]. EOF menggunakan properti dari aljabar matriks dan koefisien temporal yang terasosiasi. Adapun algoritma EOF yang diterapkan berupa kode Matlab yang dimodifikasi dari Shi et al adalah sebagai berikut [14].

1) Pertama sebuah dataset yang sudah dalam bentuk grid digunakan, terdiri atas sebuah field ruang dan waktu $\mathrm{X}(\mathrm{t}, \mathrm{s})$.

2) Kedua covariance matriks (S) dari $X(t, s)$ dihitung dengan persamaan 3 .

$S=\frac{1}{n-1} X^{T} X$

Selanjutnya menghitung eigen value dan egien vector dari covariance tersebut. Eigen value diurutkan secara terbalik dari nilai terbesar ke nilai terkecil. EOF adalah eigen vector yang terkorespondensi dengan eigen value dan EOF juga merupakan pola spasialnya. Penjumlahan dari semua eigen value disebut sebagai trace matriks, rasio antara eigen value terhadap trace menjelaskan variance dari EOF. EOF mode pertama dan principal component yang terkoresponden akan menjelaskan mayoritas dari total variance data. Karena itu EOF mode pertama dan principal component yang terkoresponden berisi informasi mayoritas tentang data asli. Umumnya varians yang mencapai $85 \%$ disebutkan telah sesuai kebutuhan, namun dapat berubah untuk aplikasi yang spesifik [14].

3) Ketiga principal component $(P C)$ dihitung, dalam hal ini $\mathrm{PC}$ adalah nilai temporal atau time series.

\section{Metodologi}

Data yang digunakan adalah data prediksi perubahan garis pantai Pantai Lebih selama 91 bulan (tahun 2005 hingga 2014) dengan 45 buah data spasial sebagai hasil dari pemodelan satu dimensi yang disebut oneline model [4], [5]. Berdasarkan gambar 1, penelitian diawali dengan inisialisasi matriks inputan. Matriks spasialtemporal yang tidak dikurangi mean akan masuk ke perhitungan EOF 1 sedangkan matriks yang dikurangi dengan mean data akan akan masuk ke perhitungan EOF 2. Kedua matriks akan dihitung covarian, eigen value, eigen vector, principal component hingga didapatkan eigen value lima terakhir, eigen vector lima terakhir, trace, principal component serta varian data. Berdasarkan perhitungan EOF 1dan EOF 2 maka dapat dibandingkan hasil eigen value, eigen vector, principal component, trace matriks dan ordinat spasialtemporal mode 1. Hasil pembandingan parameterparameter tersebut akan digunakan sebagai dasar pengambilan kesimpulan sebagai langkah akhir penelitian ini.

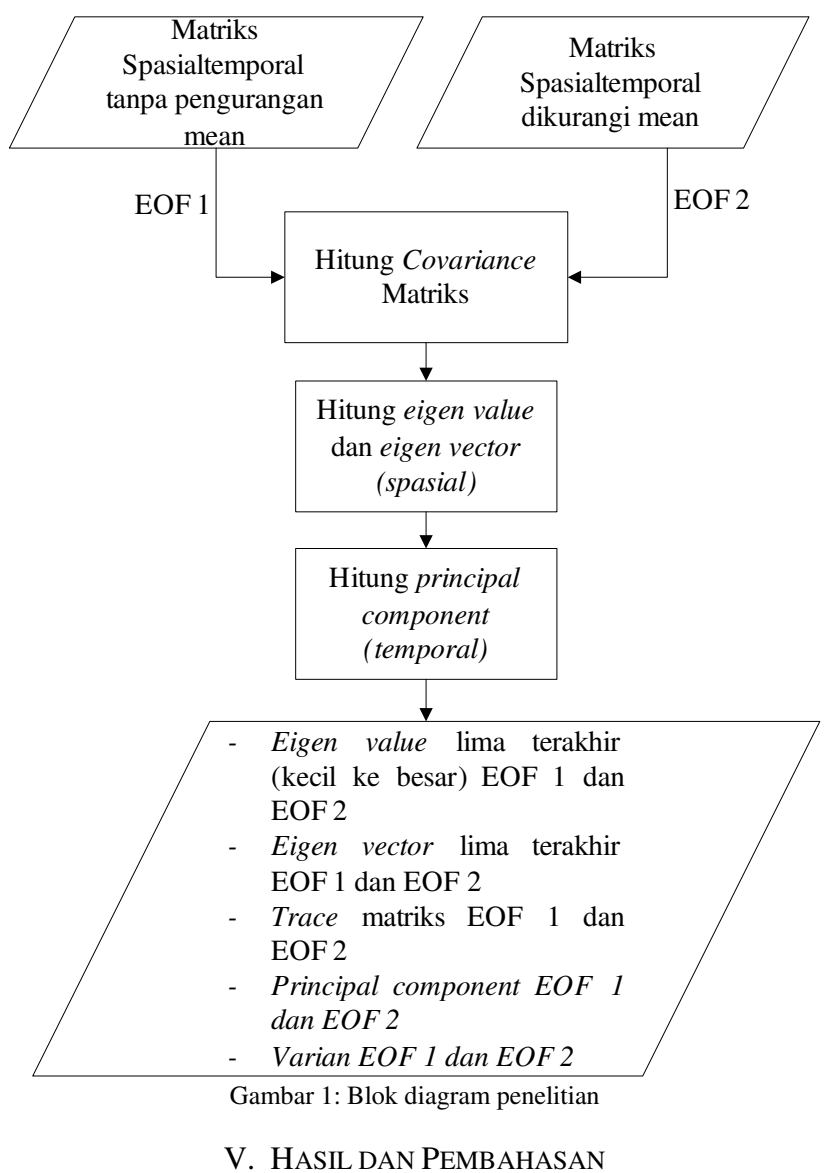

Proses pengurangan mean dilakukan pada kolom matriks sehingga mean tiap kolom menjadi 0 . Sebagai asumsi matriks A adalah matriks $\mathrm{m} \times \mathrm{n}$ perubahan garis pantai. Baris ke-1 hingga baris ke-m menyatakan nilai perubahan spasial garis pantai dan kolom ke-1 hingga kolom ke-n menyatakan perubahan secara temporal. Tiap-tiap kolom dicari nilai mean, kemudian nilai awal masing-masing kolom dikurangkan dengan mean masing-masing sehingga didapat nilai kolom (temporal) yang mean-nya menjadi 0 . 
TABEL I

VARIAN DATA, EIgen VALUE DAN TRACE EOF 1 DAN EOF 2

\begin{tabular}{|c|c|c|c|}
\hline Mode ke- & Eigen value & Trace & Yarian data (\%) \\
\hline 1 & 20073000.339 & \multirow{5}{*}{20189236.282} & 99.42427 \\
\hline 2 & 64683.443 & & 0.320386 \\
\hline 3 & 7095.160 & & 0.035143 \\
\hline$\overline{4}$ & 4939.771 & & 0.024467 \\
\hline 5 & 4526.015 & & 0.022418 \\
\hline & & Total varian & 99.82668 \\
\hline
\end{tabular}
didapatkan bahwa eigen vector mode pertama hingga kelima eigen value lima terakhir, trace matriks hingga variance menunjukkan hasil yang sama. Principal component yang menunjukkan hasil yang berbeda antara EOF 1 dengan EOF 2, yang sangat sejalan dengan penelitian Miranda et al yaitu principal component mode pertama mungkin akan terkoresponden lebih atau kurang terhadap mean dari data [12]

Eigen vector pada penelitian ini diwakili oleh eigen vector mode pertama seperti disajikan pada gambar 2. Jarak $\mathrm{x}$ (horisontal) pada grafik menunjukkan garis pantai yang dibagi ke dalam pias atau sel yang masing-masing jaraknya adalah $20 \mathrm{~m}$. Nilai EOF (vertikal) adalah nilai eigen vector hasil perhitungan. Grafik menggambarkan bahwa pada arah sejajar pantai terjadi perubahan yang sangat signifikan yaitu di sepanjang pantai dan di sebagian besar pias cenderung menunjukkan terjadinya akresi atau kemajuan garis pantai (nillai EOF positif).

Shi, et al menyebutkan bahwa rasio dari eigen value $\lambda_{\mathrm{m}}$ ke trace $(\mathrm{S})$ menjelaskan varians mode ke $\mathrm{m}$ dari EOF. Selain itu juga disebutkan bahwa umumnya varians yang mencapai $85 \%$ disebutkan telah sesuai kebutuhan, namun dapat berubah jika diperlukan untuk aplikasi yang lebih spesifik [12]. Penelitian ini menghasilkan mode pertama yang memiliki varian data sebesar $99.42 \%$ dari lima mode komponen EOF yang dihitung seperti ditampilkan tabel I. Hasil ini didukung oleh penelitan Alvarez dan Pan yaitu dengan menggunakan komponen EOF mode pertama dari 3 hingga 4 mode komponen $E O F$ akan cukup untuk mewakili mayoritas data asli [6].

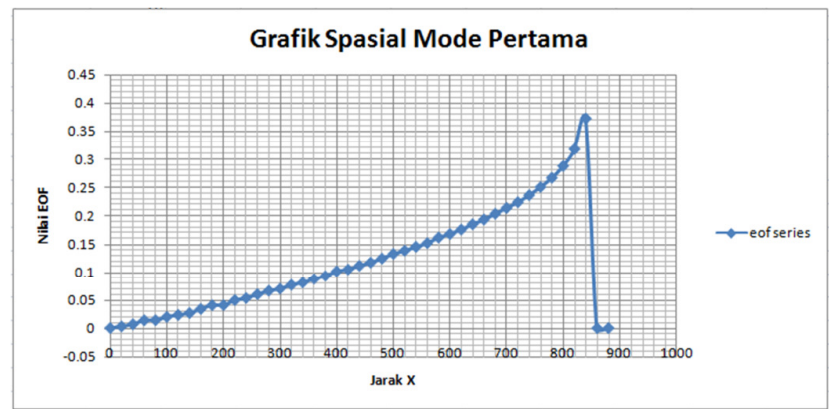

Gambar 2: Eigen vector mode kesatu (EOF 1 dan EOF 2)

Perbedaan yang signifikan terdapat pada hasil principal component mode pertama baik EOF 1 maupun EOF 2 (gambar 3 dan gambar 4). Grafik secara horisontal menjelaskan perubahan temporal garis pantai dari bulan ke-1 hingga bulan ke-91. Secara vertikal menunjukkan nilai perubahan principal component yang dihasilkan. Dari grafik hasil EOF 1 didapatkan bahwa nilai temporal bulan ke-1 menghasilkan nilai positif, kemudian bulan ke-2 hingga bulan ke-91 hasil bernilai minus. Pada EOF 2 nilai principal component ke-1 hingga bulan ke-37 berada pada posisi positif, selanjutnya dari bulan ke-38 hingga bulan ke-91 menghasilkan nilai negatif. Kemudian untuk kedua gambar (gambar 3 dan gambar 4) grafik juga menunjukkan garis pantai terus mengalami kemunduran dari bulan ke-1 hingga bulan ke-58, selanjutnya bulan ke-59 hingga bulan ke-91 garis pantai hanya mengalami sedikit pergeseran baik maju ataupun mundur

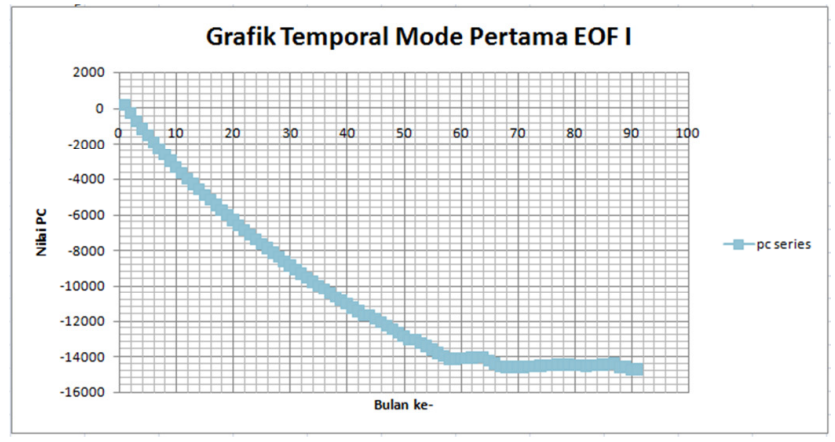

Gambar 3: Principal component mode kesatu EOF 1

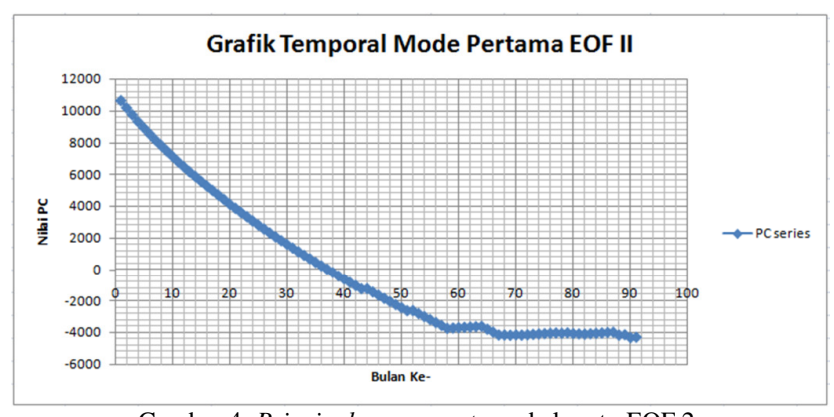

Gambar 4: Principal component mode kesatu EOF 2

Meskipun keduanya menghasilkan besaran tanda dan nilai yang berbeda tetapi tetap menunjukkan kecenderungan erosi atau cenderung menunjukkan terjadinya kemunduran garis pantai. Hal ini berarti jika dua buah asumsi dari penelitian Alvarez dan Pan diterapkan akan menghasilkan perubahan temporal garis pantai yang berbeda. Ketika data awal tanpa dikurangi mean yaitu jika diasumsikan bahwa perubahan profil pantai tidak stabil dan sedang berevolusi maka hasil principal component atau perubahan garis pantai secara temporal seperti pada gambar 3. Jika data awal dikurangi mean yang diterapkan maka perubahan profil pantai sudah dalam keadaan sekitar setimbang berarti perubahan garis pantai secara temporalnya seperti pada gambar 4 .

\section{KESIMPULAN}

Dengan perlakuan yang berbeda sebelum diterapkan metode EOF yaitu EOF 1 tidak ada pengurangan mean pada dataset awal dan EOF 2 dataset awal dikurangi dengan mean data maka dari hasil pembandingan parameter hasil EOF didapatkan bahwa baik EOF 1 ataupun EOF 2 memberikan 
informasi nilai eigen vector, nilai trace, dan eigen value yang sama. Sedangkan pada hasil principal component terdapat perbedaan yang signifikan. Hal ini membuktikan jika mean tidak dikurangi dari dataset awal perubahan garis pantai maka akan terdapat perilaku mean di hasil perubahan temporal EOF atau hasil perubahan garis pantai secara temporal akan tergantung dari asumsi dan studi awal keadaan profil pantai.

\section{REFERENSI}

[1] Ariasih, N., I Putu Agung Bayupati , I Ketut Gede Darmaputra. Sistem Pendukung Keputusan Pemilihan Lokasi TPA Sampah Menggunakan Metode Min_Max Inference Fuzzy. Majalah Ilmiah Teknologi Elektro, Vol.14 No. 1. Jun. 2015.

[2] Arnawa, I., I G. A. P. Raka Agung. Prototipe Monitoring Ketinggian Air Bendungan Melalui Media Sosial Twitter Berbasis Mikrokontroler Atmega-328PU. Majalah Ilmiah Teknologi Elektro. Vol. 14 No.2. Dec. 2015.

[3] Putra, I.S. Segmentasi Citra Remote Sensing Laut Dengan Metode Clustering DBSCAN. Majalah Ilmiah Teknologi Elektro, Vol. 12 No.2. Dec. 2013.

[4] Dabees, M.A., Efficient Modeling of Beach Evolution. Disertation. Queen's University, Kingston, Ontario, Canada. 2000.

[5] Purnaditya, N.P., I Gusti Bagus Sila Dharma, I Gusti Ngurah Putra Dirgayusa. Prediksi Perubahan Garis Pantai Nusa Dua dengan OneLine Model. Jurnal Ilmiah Elektronik Infrastruktur Teknik Sipil. Universitas Udayana. 2012.

[6] Alvarez, F. dan Pan, S. Modelling Long-Term Coastal Morphology Using EOF Method. Proceeding. Thirthy Fourth Conference on Coastal Engineering. 2014.
[7] Kuriyama, Y. Masayuki Banno, Hiroyuki Kishi, Toshifumi Satoh and Kunio Mizuuchi. Morphological Change Of Nourished Beach Behind Submerged Breakwater on The Niigata Coast. Seventh International Conference on Coastal Dynamics 2013, p.1015 - 1024. 2013.

[8] Arkwright D. dan Suntoyo. Application Of Empirical Orthogonal Function Models To Analyze Shoreline Change At Bangkalan Madura. Makara, Teknologi, Vol. 15, No. 2, November 2011: 153-160. 2011.

[9] Luhwayudin M., Suntoyo, dan Wahyudi Citrosiswoyo. Analisa Perubahan Garis Pantai Tegal dengan Menggunakan Empirical Orthogonal Function (EOF). JURNAL TEKNIK ITS Vol. 1, (Sept, 2012) ISSN: 2301-9271. 2012.

[10] Azhar M. R., Suntoyo, Mahmud Musta'in. Analisa Perubahan Garis Pantai Tuban, Jawa Timur dengan Menggunakan Empirical Orthogonal Function (EOF). JURNAL TEKNIK ITS Vol. 1, No. 1(Sept. 2012) ISSN: 2301-9271. 2012.

[11] Ivanoviq A, Suntoyo, S, Kriyo. Analisa Karakteristik Perubahan Garis Pantai Lebih Kabupaten Gianyar dan Kondisi Lingkungan Sekitar dengan Empirical Orthogonal Function (EOF). Tugas Akhir Teknik Kelautan FTK-ITK. Surabaya. 2011.

[12] Miranda, A.A., Le Borgne, Y. \& Bontempi, G. New Routes from Minimal Approximation Error to Principal Components. Neural Processing Letters. Springer. Vol. 27. P.197-207. doi:10.1007/s11063007-9069-2. 2008

[13] Alvarez, F. dan Pan, S. Predicting Coastal Morphological Changes with Empirical Orthogonal Function Method. Water Science and Engineering 2016, 9(1): 14-20. 2016.

[14] Shi, R.X., J.F. Wang, C.D. Xu, S.J. Lai, W.Z. Yang. Spatiotemporal Pattern of Hand-Foot-Mouth Disease In China: An Analysis of Empirical Orthogonal Functions. Elsevier. P.367-375. 2014. 
\{ halaman ini sengaja dikosongkan \} 